\title{
Studies on the Atmospheric Ion Spectrum
}

-- Procedures of Experiments and Data Analysis -

\author{
by \\ M. Misaki \\ Meteorological Research Institute, Tokyo \\ (Received June 12, 1.961)
}

\begin{abstract}
A newly designed apparatus for measuring the mobility spectrum of atmospheric ions was constructed in 1959, on the basis of the method previously developed by the author. After the examination of the air flow pattern through the aspiration cylinder, measurements of the mobility spectrum have been resumed since 1960 .

Two ion probes were used in the present studies with different diameters and with the same length to scan the mobility ranges of 30.1 and $0.1-0.005 \mathrm{~cm}^{2} /$ volt $\mathrm{sec}$, respectively.

Dedails on the experimental set-up, procedures of experiments and practical treatments of data analysis are described in this paper.
\end{abstract}

\section{Introduction}

Previously the author (MISAKI: 1950) introduced a new method of measuring the mobility spectrum of atmospheric ions, together with an example of actual measurement by this method. The observations of ion concentration, especially the measurements of the mobility spectrum, involve many difficulties. They are apt to be disturbed by various factors which are out of our control. First of all, the air stream going through the ion chamber is required to be laminar. This is, in general, very difficult to realize practically, though it is the first necessary condition to improve accuracy of measurement.

Recently I have newly designed and constructed an aspiration chamber (MISAKI : 1960), and examined the air flow pattern going through it. From the result of this examination, the appropriate air flow rate was determined at which the air stream is kept laminar. With this new apparatus, we have resumed the measurements of the mobility spectrum since 1960 .

The main purpose of the present experiment is to determine as exactly as possible the fine structure of the spectrum in the region of the small ion group.

In this paper, the descriptions of the experimental set-up, the procedures and the treatments of observational data are given*.

* Recently E.C. WhIPPLE, Jr. (1960) has improved this method. The characteristics of his method are normalized with reference to the applied voltage before being differentiated. Though the procedure of Whipple's analysis is almost the same with the present author's, it has a sure advantage in experimental procedure, since in his method only the current to the second electrode needs to be measured. The experiments hereafter shall be tried with his modified method. 


\section{Experimental set-up}

\section{1) Description of the aspiration cylinder}

The aspiration cylinder through which the air flow pattern was examined in preliminary investigation, was reconstructed for the present purpose. The schematic diagram of the cylinder is shown in Fig. 1.

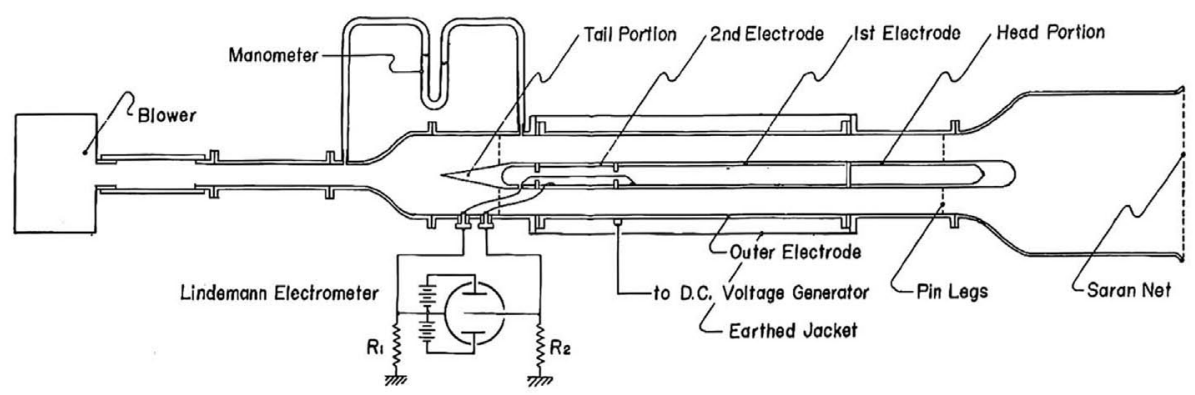

Fig. 1. The schematic diagram of the ion mobility spectrometer.

The ion-probe placed along the axis of the cylinder is divided into four portions. The head and the tail portions are grounded, the longer one of the two portions between them serving as the first electrode and the other as the second one. The portions are joined to each other firmly with three insulating spacers between them. Since these brass cylinders and teflon spacers of $6 \mathrm{~mm}$ in width have the same radius, the probe has an entirely smooth surface even at these junctures.

This probe is supported and settled in the outer cylinder by the and of four pin legs implanted at the head and the tail portions. Lead wires connected with the first and the second electrode respectively are passed through the inside of the probe cylinder and drawn out at the tail portion. Thus the probe has neither legs nor lead wires, which might cause undesirable disturbances in the air stream and the electric field, within the electric field between the collecting electrodes. Eddies caused at the head of the probe, or at the pin legs, dissipate before they reach the portion of the collecting electrode, where, then, the air stream is kept laminar. Undesirable effects of a stray flux of the electric field which terminates at the head portion will be discussed later.

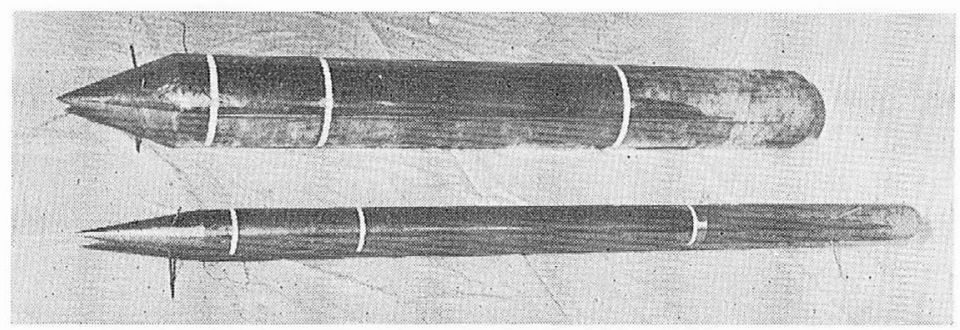

Fig. 2. Two types of the ion probes.

Two probes have been constructed in order to scan the different ranges of the 
ion mobilities. The slender one, called the small-ion probe, is designed to measure for the mobility range between 3.0 and $0.1 \mathrm{~cm}^{2} / \mathrm{volt}$. sec, and has a diameter of $5 \mathrm{~cm}$. The lengths of its first and second electrodes are $45 \mathrm{~cm}$ and $15 \mathrm{~cm}$ respectively. Another probe, called the intermediate-ion probe, is used in order to scan for the range between 0.1 and $0.005 \mathrm{~cm}^{2} /$ volt. sec, and has a diameter of $12 \mathrm{~cm}$. The lengths of both electrodes of it are the same with those of the small-ion probe. They are shown in Fig. 2.

The aspiration cylinder has a wide opening of $30 \mathrm{~cm}$ diameter. Two sheets of saran net (synthetic fiber) were placed at this entrance to prevent the inflowing of eddies from outside. The air stream from this wide opening is squeezed as it goes into the chamber, the diameter of which is $15 \mathrm{~cm}$. The squeezing curve of this portion has been drawn by the following formula:

$$
\left(\frac{r_{1}}{r}\right)^{2}=\left(\frac{r_{1}}{r_{0}}\right)^{2}\left(1-\left\{1-\left(\frac{r_{0}}{r_{1}}\right): \frac{2\left(1-\frac{x^{2}}{l^{2}}\right)^{2}}{\left(1+\frac{x^{2}}{3 l^{2}}\right)^{2}}\right),\right.
$$

where $r_{1}$ and $r_{0}$ denote the radius of the opening and of the inner radius of the outer cylinder, and $r$ is the radius at $x$ which is the co-ordinate along the axis. Squeezing begins at $x=0$ and ends at $x=l$.

The portion of the outer cylinder which faces the inner electrodes is insulated by bakelite spacers and serves as the outer electrode of the condenser. The potential from a D.C. voltage source is applied to this electrode. The whole picture of the equipment assembled for the experiments is shown in Fig. 3.

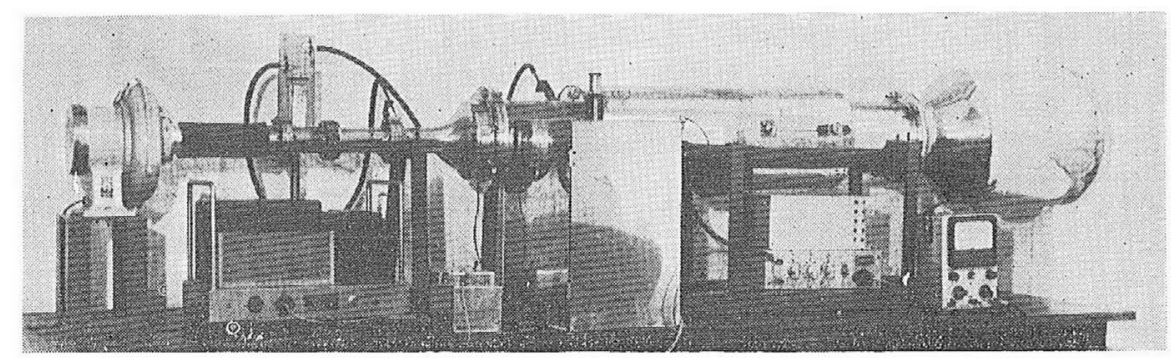

Fig. 3. Experimental set-up for obtaining the ion spectrum.

\section{2) Description of the electrometer system}

The current $i_{1}$, and $i_{2}$, consisting of ions collected by the first and the second electrode, flow to the ground through the high resistors $R_{1}$ and $R_{2}$ respectively, and develop the voltages $v_{1}$ and $v_{2}$ across each of them. A Lindemann electrometer is used to measure the potential difference $v_{1}-v_{2}$. The case of the electrometer is insulated by three teflon bosses and connected with the first electrode, whereas its needle is connected with the second electrode. Therefore, the deflection of the needle is proportional to $v_{1}-v_{2}$.

Since the experimental procedure based upon the author's method requires to 
plot the value $\frac{i_{1}}{a_{1}}-\frac{i_{2}}{a_{2}}$ against the potential applied to the outer electrode, it is convenient if $v_{1}-v_{2}$ is proportional to $\frac{{ }^{*} i_{1}}{a_{\mathrm{i}}}-\frac{i_{2}}{a_{2}}$.

Since $v_{1}=i_{1} R_{1}$ and $v_{2}=i_{2} R_{2}$,

$$
\frac{i_{1}}{a_{1}}-\frac{i_{2}}{a_{2}}=\frac{v_{1}}{a_{1} R_{1}}-\frac{v_{2}}{a_{2} R_{2}}
$$

Now, if we choose the values $R_{1}$ and $R_{2}$ so as to make $\frac{R_{1}}{R_{2}}=\frac{a_{2}}{a_{1}}$, the above formula becomes equal to $\frac{1}{a_{1} R_{1}}\left(v_{1}-v_{2}\right)$.

Considering that the Lindemann electrometer used has the voltage sensibility of about 0.02 volt/scale div. and that the current to the electrode is of the order of $10^{-13} \mathrm{amp}, R_{1}$ has been decided to be $1 \times 10^{12} \Omega$, and consequently $R_{2}$ be $3 \times 10^{12} \Omega$ since $\frac{R_{1}}{R_{2}}=\frac{a_{2}}{a_{1}}=\frac{l_{2}}{l_{1}}=\frac{1}{3}$.

The time constants of the two systems must be equal, because it is necessary for the two systems to be dynamically balanced. If $C_{1}$ denotes the capacity** of the first electrode system and $C_{2}$ that of the second one, the relation

$$
C_{1} R_{1}=C_{2} R_{2}
$$

must hold. For this purpose, $C_{1}$ was adjusted by adding suitable capacity. The values of $C_{1}, C_{2}$ etc. are shown in Table 1.

\begin{tabular}{|c|c|c|c|c|c|c|}
\hline & $C_{1}$ & $C_{2}$ & $C_{3}$ & $C_{1} R_{1}$ & $C_{2} R_{2}$ & Half-value time \\
\hline small-ion probe & $76^{\mathrm{pF}}$ & $26^{\mathrm{pF}}$ & $7^{\mathrm{pF}}$ & $79^{\sec }$ & $81^{\sec }$ & $55^{\sec }$ \\
\hline $\begin{array}{l}\text { intermediate-ion } \\
\text { probe }\end{array}$ & 246 & 82 & 18 & 256 & 257 & 177 \\
\hline
\end{tabular}

Table 1. Constants of the electrometer system.

The time constants of both systems are given in the fourth and the fifth column, where $R_{1}=1.04 \times 10^{12} \Omega$ and $R_{2}=3.13 \times 10^{12} \Omega$.

* The constants $a_{1}$ and $a_{2}$ are calculated from

$$
a_{j}=l_{j} / 2 \ln \frac{r_{0}}{r_{i}} \quad(j=1,2)
$$

where $r_{i}$ and $r_{0}$ represent the radii of the inner and outer electrodes, and $l_{1}, l_{2}$ are the lengths of them, respectively. Therefore, $a_{j}$ is the capacity of the cylindrical condenser divided by the dielectric constant of air.

For the small-ion probe, $a_{1}=20.48 \mathrm{~cm}$ and $a_{2}=6.83 \mathrm{~cm}$, and for the intermediate-ion probe, $a_{1}=100.8 \mathrm{~cm}$ and $a_{2}=33.6 \mathrm{~cm}$.

** Because the two systems of the first and the second electrode have a certain amount of coupling capacity $C_{3}$ between them which can not be neglected, $C_{1}$ and $C_{2}$ are computed considering the effect of $C_{3}$. Accordingly, when the second electrode system is grounded, as in the case of measuring the ordinary voltage vs current characteristics, $C_{1}$ increases slightly. 
As readily seen from the values of the time constant, it takes much time before the indication of electrometer attains to the final value. Therefore, reading of electrometer indication is made at the time when it attains to the half value of the final one after it starts from zero potential. These half value times, calculated from the time constants, are shown in the last column.

The insulation resistance of both electrodes of the probe must be kept at least about two orders of magnitude higher than $R_{1}$ or $R_{2}$. Teflon insulators have served satisfactorily for this purpose.

\section{3) D.C. supply to the outer electrode}

Potential of the outer electrode is supplied from a D.C. source which consists of a stabilizer, a rectifier and a potential divider. 500 volt D.C. generated from a rectifier is potentiometrically divided in 20 or 30 steps with an equal interval on the logarithmic scale. In the experiments carried out at Karuizawa, where the fluctuation of A.C. voltage occurred frequently, dry batteries were used.

\section{4) Stray flux at the entrance of the electrode}

In the preliminary tests of our experiments, it was found that some fractions of ions are removed before they reach the first electrode. Since the grounded metal wall of the outer cylinder, and the head portion of the probe are just in front of the electrodes, a stray flux from the outer electrode terminates on both. Therefore, some of the ions introduced into the chamber are caught before reaching the electrode owing to this stray flux.

In order to reduce this effect as much as possible, a wide spacer of the insulator was first inserted between the head portion of the probe and the first electrode, and another spacer at its opposite position in the outer cylinder, with a view to keeping these grounded metal parts away from the electrodes. A cylinder made of plastics (acrylic acid resin) with a length of $20 \mathrm{~cm}$ was used as a spacer in the outer cylinder, and a bakelite pipe of the same length as a spacer in the probe.

This attempt, however, has ended in failure, because observations are seriously disturbed by the fluctuating induction caused perhaps by unsettled distribution of charge on the surface of these insulators, or by alteration of the potential (relaxation) at them. Thus, these insulating spacers were removed finally and the chamber has been restored again.

A detailed description of the effects of the stray flux at the entrance of the electrode will be presented later.

\section{Experimental procedure}

\section{1) Scanning range}

Descriptions of the theory on the method of measurements have been given in the previous paper (MISAKI : 1950). In the following, further details regarding the practical procedure of experiments performed with the newly constructed apparatus are given.

There is a well-known relation between the air flow rate $\Phi$, the potential $V$ ap- 
plied to the outer electrode and the critical mobility $\kappa_{c}$ (e.g. for the first electrode), that is

$$
\kappa_{c}=\frac{\Phi}{4 \pi a_{1}} \frac{1}{V}
$$

where the constant $a_{1}$ is $20.48 \mathrm{~cm}$ for the small-ion probe and $100.8 \mathrm{~cm}$ for the intermediate-ion probe as already described. The above relation is shown in Fig. 4.

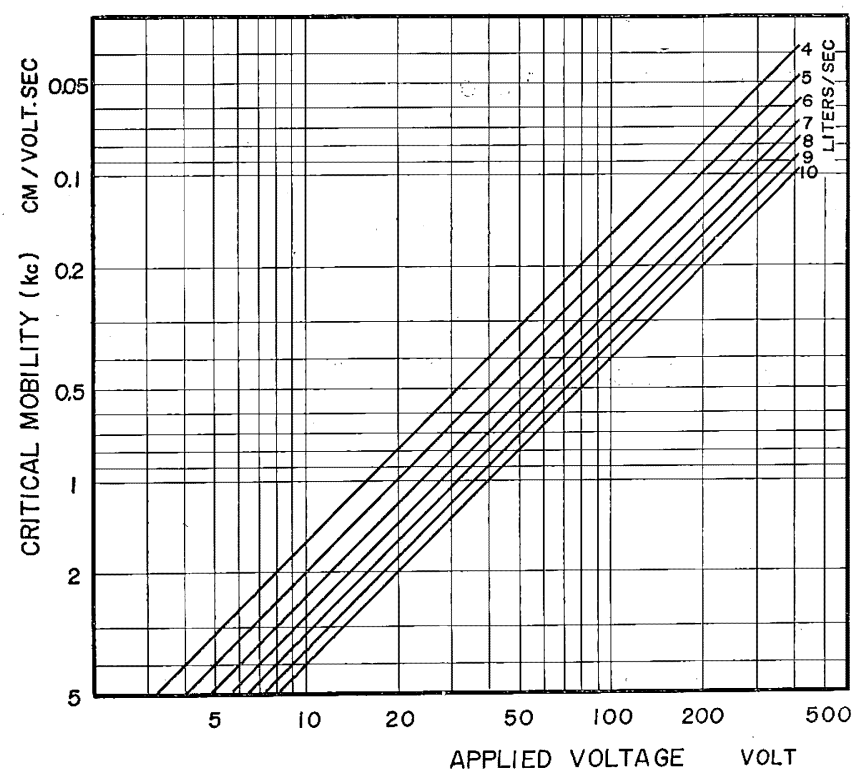

Fig. 4. The relation between air flow rate, applied voltage and critical mobility for the first electrode. (in the case of the small-ion probe)

The appropriate air flow rate at which the air stream is kept laminar, in the case of the small-ion probe, has been found by the previous work to be from about $4 l / \mathrm{sec}$ to $9 l / \mathrm{sec}$, so that the experiments with the small-ion probe have been carried out at the flow rate of $7.5 \mathrm{l} / \mathrm{sec}$.

Now, the maximum voltage applied to the outer electrode from the D.C. generator is 500 volts. Therefore the lower limit of a mobility range which can be scanned with this arrangement is seen from Fig. 4 to be about $0.1 \mathrm{~cm}^{2} /$ volt. sec. Further lower regions, down to $0.005 \mathrm{~cm}^{2} /$ volt. sec., can be scanned with the intermediate-jon probe and with the same D.C. supply at the air flow rate of about $5 l / \mathrm{sec}$.

\section{2) Resolution of the spectrum and steps of applied voltage}

From the method upon which the present work is based, the concentration of ions with mobilities between $\kappa_{c}$ and $\kappa_{d}$ is to be deduced. The relation of $\kappa_{c}$ to $\kappa_{d}$ is given as follows :

$$
\kappa_{d}=\frac{a_{1}}{a_{1}+a_{2}} \kappa_{c}
$$


then,

$$
\log \kappa_{c}-\log \kappa_{d}=\text { const. }
$$

that is to say, ion concentration is given for every section of mobility axis divided at equal interval on the logarithmic scale*. Thus it will be seen that the value of $\frac{a_{1}}{a_{1}+a_{2}}$ gives a measure of resolutions of the spectrum.

Accordingly, plots of the characteristic curve $\frac{i_{1}}{a_{1}}-\frac{i_{2}}{a_{2}}$ vs $V$ should be taken, at least, at every voltage which corresponds to the particular interval described above.

The voltage interval, with which measurements were made stepwise, was somewhat finer than that. Table 2 shows such a sequence steps of voltage $V$ applied to the outer electrode.

Table 2. Voltages at 20 steps.

(volt)

\begin{tabular}{l|c|c|c|c|c|c|c|c|c|c}
\hline \hline Step No. & 1 & 2 & 3 & 4 & 5 & 6 & $7 \ldots$ & 8 & 9 & 10 \\
\hline Voltage & 3.20 & 4.80 & 6.3 & 7.9 & 9.5 & 12.7 & 15.7 & 22.2 & 28.5 & 37.6 \\
\hline \hline Step No. & 11 & 12 & 13 & 14 & 15 & 16 & 17 & 18 & 19 & 20 \\
\hline Voltage & 51 & 67 & 90 & 116 & 152 & 198 & 270 & 345 & 461 & 610 \\
\hline
\end{tabular}

It takes considerably much time to complete all measurements at every step. Sometimes when the observed characteristic curve is almost flat, measurements at some steps were skipped over.

Since the time required for one reading for one step is fairly long owing to the fact that the electrometer system has rather a large time constant, actual readings were made at the half value time as already mentioned. In spite of this, one series of measurements for scanning the intended mobility range still requires much time. For example, in the case with the small-ion probe, it takes about 20 minutes to scan the range between $3-0.1 \mathrm{~cm}^{2} /$ volt. sec. Therefore, conditions of ions in the atmosphere may vary within this time. To ascertain whether conditions have varied or not during the experiment, measurement was repeated at an appropriate step after the scanning was completed. When appreciable difference was found between them, the data of the experiment were not used.

* Chr. Junge (1958) has made a proposal as follows:

Considering the wide range of particle sizes and concentrations, it seems advisable to use the logarithmic scale. The log-radius distribution can thus be defined by

$$
n(r)=d N / d(\log r) \text {. }
$$

For the same reason, our mobility spectrum should be represented in a similar from. Fortunately, the data obtained by this method gives the ion concentration $\Delta N$ in the particular interval $\Delta(\log \kappa)$, where

$$
\Delta(\log \kappa)=\log \frac{a_{1}+a_{2}}{a_{1}}=0.1249
$$

So that the spectrum will be easily converted into the form

$$
n(\kappa)=\Delta N / \Delta(\log \kappa)=\Delta N / 0.1249 \text {. }
$$


The atmospheric conditions in fair weather were so stable that most of the data were available.

\section{Procedure of data analysis}

\section{1) General description of the procedure of analysis}

The potential difference between the first and the second electrode obtained from the electrometer reading is converted to $\frac{i_{1}}{a_{1}}-\frac{i_{2}}{a_{2}}$ by eq. (1). Then the characteristic curve, $V$ vs $\frac{i_{1}}{a_{1}}-\frac{i_{2}}{a_{2}}$, is ready to be plotted. Fig. 5 shows an example of the characteristics. Critical mobility for the first electrode, $\kappa_{c}$, is scaled in the abscissa as well as the corresponding $V$.

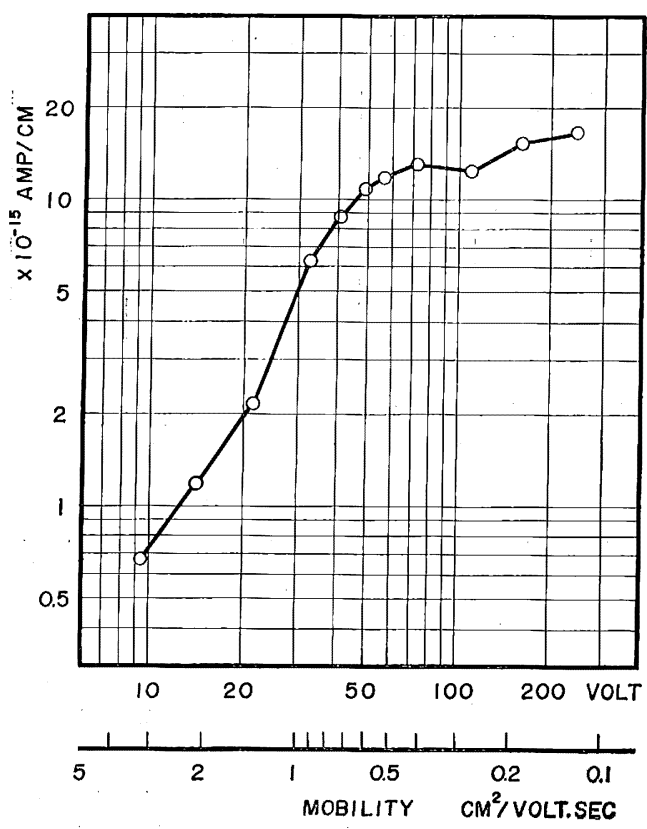

Fig. 5. An example of the characteristic curve, $\frac{i_{1}}{a_{1}}-\frac{i_{2}}{a_{2}}$ vs $V$.

(Apr. 8 1960, 8hr. positive ion)

The concentration of ions with mobility between $\kappa_{c}$ and $\kappa_{d}$ is deduced from

$$
\int_{\kappa_{d}}^{\kappa_{c}} f(\kappa) d \kappa=\frac{1}{\bar{\kappa}} \frac{a_{2}}{4 \pi e\left(a_{1}+a_{2}\right)} \frac{d}{d V}\left(\frac{i_{1}}{a_{1}}-\frac{i_{1}}{a_{2}}\right)
$$

where $\bar{\kappa}=\frac{1}{2}\left(\kappa_{c}+\kappa_{d}\right)$, and the differentiation in the right hand side of the equation is to be taken at $V$ corresponding to $\kappa_{c}$ (eq. (3)). $\kappa_{d}$ is related to $\kappa_{c}$ by eq. (4), and it follows in our apparatus as $\kappa_{d}=0.75 \kappa_{c}$.

Then, it is necessary to determine the slopes of the curve with appropriate intervals. This was done at every measuring step as follows: denoting 


$$
\frac{i_{1}}{a_{1}}-\frac{i_{2}}{a_{2}}=X
$$

then,

$$
\left(\frac{d X}{d V}\right)_{V=V n}=\frac{1}{2}\left[\frac{X_{n}-X_{n-1}}{V_{n}-V_{n-1}}-\frac{X_{n+1}-X_{n}}{V_{n+1}-V_{n}}\right]
$$

where $n$ is the step number of measurements. An example of spectrum thus obtained is shown in Fig. 6, which has been derived from Fig. 5.

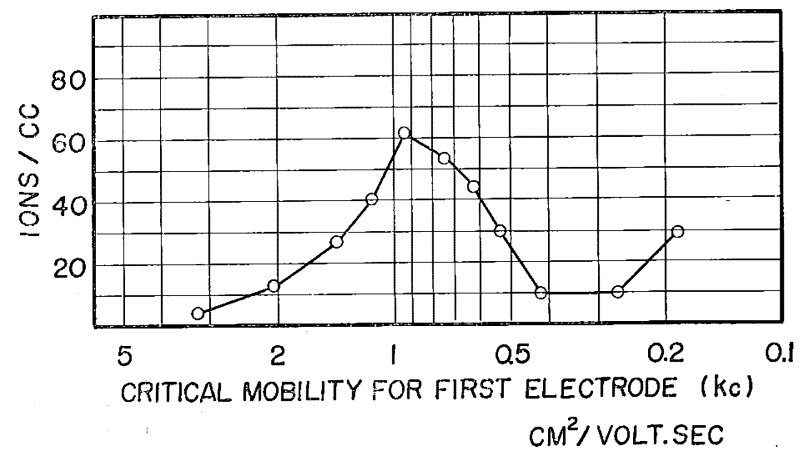

Fig. 6. Ion concentration between $\kappa_{c}$ and $\kappa_{d}$ (Derived from Fig. 5).

The expression of the spectrum in a histogram form, as is shown in Fig. 7, was given by plotting the ordinates of Fig. 6 at the voltages $V,(4 / 3) V,(4 / 3)^{2} V, \cdots \cdots$ etc.

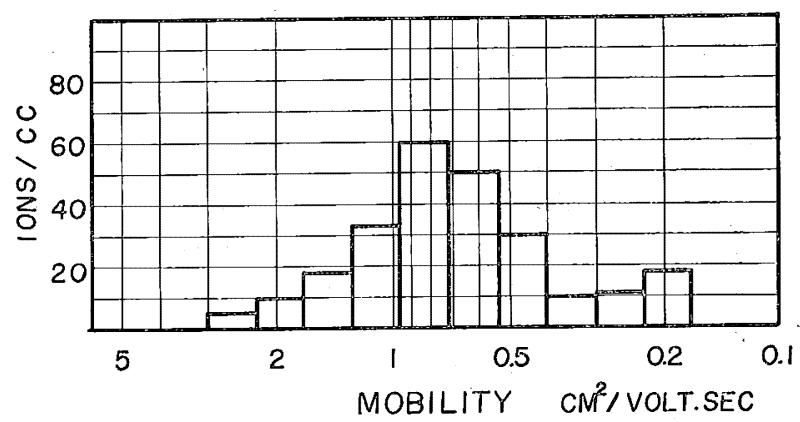

Fig. 7. An example of the mobility spectrum (derived from Fig. 6.).

\section{2) Removal of ions by the stray field at the entrance of the electrode}

The undesirable effect of the stray flux of the electric field at the entrance of the electrode in the experiment with the small-ion probe was revealed especially when the air was clean and contained rather a low concentration of ions with larger sizes than those of the small-ion group. In such a case, the characteristic curve often showed a negative slope at voltages greater than about 70 volts as shown by the broken line in Fig. 8. 


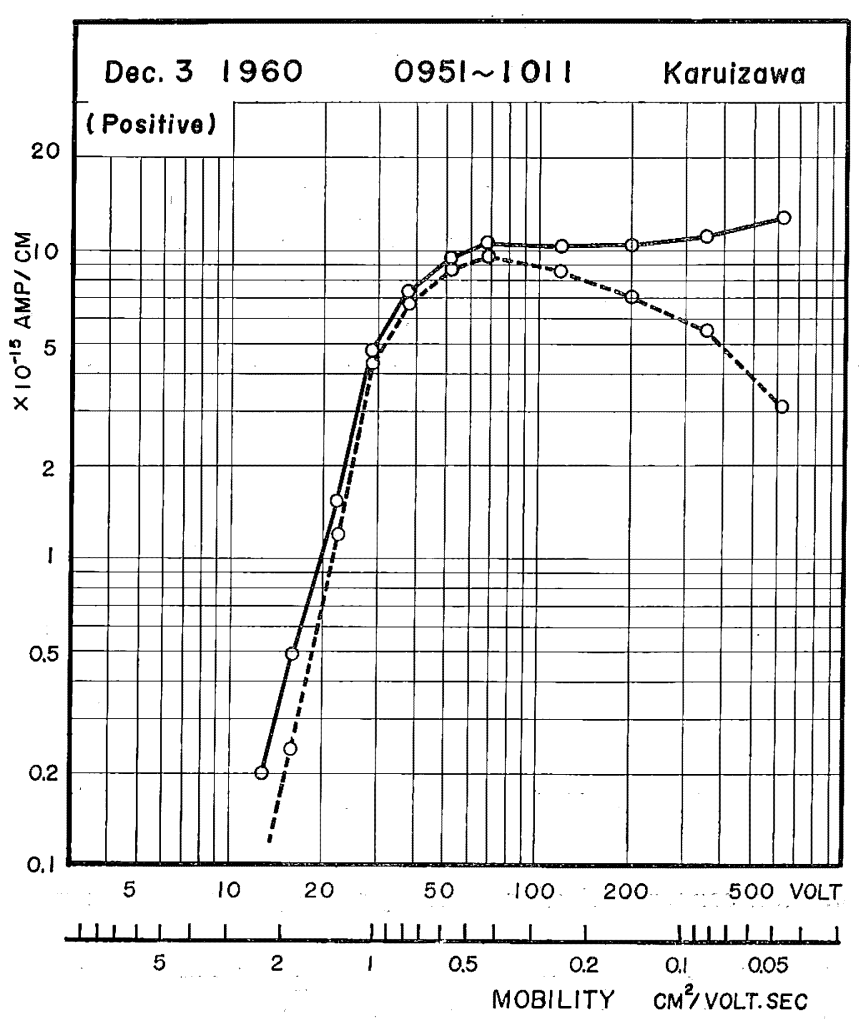

Fig. 8. Improper decrement in A-curve.

Theoretically speaking, if there is no concentration of ions within certain region of mobilities, the characteristic curve should have no slope in the region of voltage corresponding to it.

Many tests made on such a decrement of the curve with voltage have revealed that it was caused by the stray flux at the entrance. Some of the ions are removed before reaching the first electrode, which reduces, as a result, the amount of ions expected to be collected by the first electrode.

A similar effect.was found in the ordinary voltage-current characteristics. When the second electrode is grounded, leaving the connection of the electrometer system unchanged, the reading of the electrometer becomes proportional to $i_{1}$, i.e. the current into the first electrode. Then the $i_{1}$ vs $V$ curve is readily plotted. For simplicity we call this characteristic as B-curve hereafter, whereas the $\frac{i_{1}}{a_{1}}-\frac{i_{2}}{a_{2}}$ vs $V$ characteristic as A-curve. B-curve should be monotonic increasing with the first derivative of monotonic decreasing.

In the case when some portion of A-curve showed improper decrement, B-curve obtained by the successive measurements also frequently showed decrease with increasing voltage, or increase in the first derivative.

An example corresponding to Fig. 8 is shown in Fig. 9 by the broken line. 


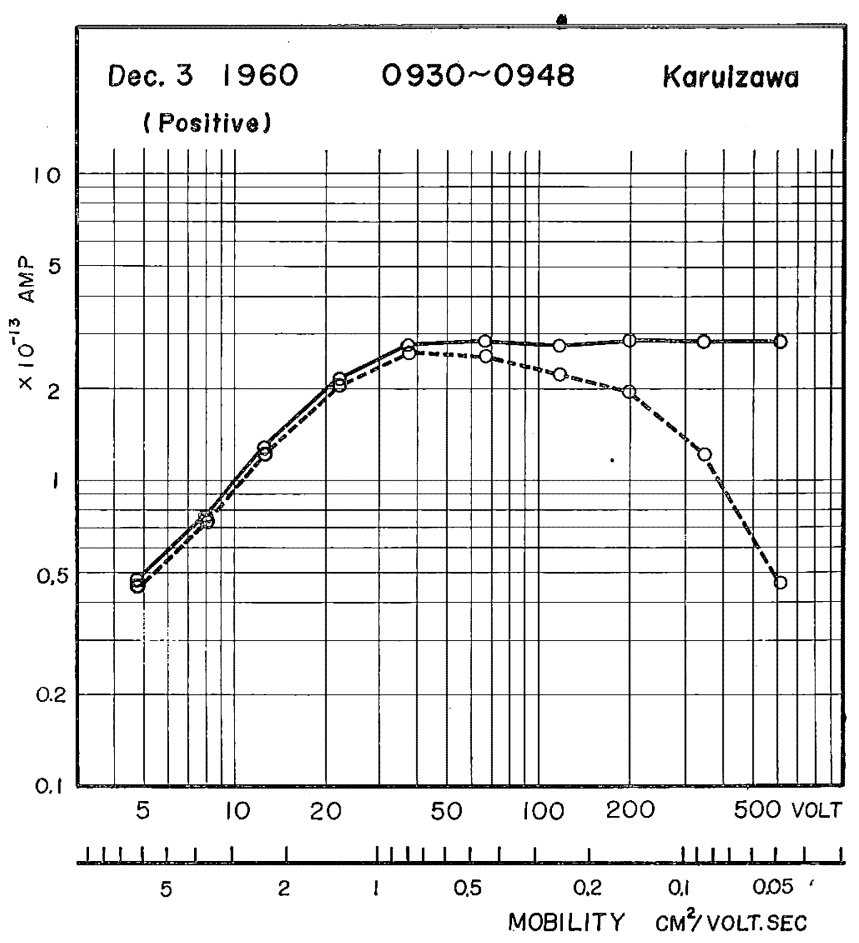

Fig. 9. Improper decrement in B-curve.

Now, the effect of the reduction in A-curve, caused by a stray field as well as in B-curve, must always exist even when it is not revealed apparently. For instance, when the air contains of the large ions, B-curve will not decrease but only increase, even though the reduction should exist.

It is impossible to give strict corrections for these observed values under the present experimental arrangements. Roughly estimated correction, however, was made, which will be mentioned below.

In the first place, it is assumed that the removal of the small ions may increase proportionally with the applied voltage, until all of the small ions are removed at a certain voltage. The removal must be added to $i_{1}$ as a correction. This assumption will roughly hold, because the small ion group can be regarded as a single line spectrum in such a wide range up to the region where the decrement of the characteristics comes to be apparent.

In the experiments carried out at Karuizawa in winter 1960, where the air was fairly clean, B-curve showed an apparent decrement. It was often reduced to zero over the voltage of 600 volts. The broken line in Fig. 9 shows such an example. Thus the critical voltage in this case, at which all small ions are removed before they reach the first electrode, has been estimated to be about 600 volts.

For simplicity we illustrate the procedure of correction by an example. As the first approximation, a provisional value of the small ion content $N^{\prime}$ was determined from A-curve shown in Fig. 8 by the broken line. $\frac{V}{600}\left(e \Phi N^{\prime}\right)$ was then added to 
each $i_{1}$ corresponding to $V$. The full line in Fig. 8 shows the plot of the corrected data. B-curve in Fig. 9 determined just before the measurement of A-curve was similarly corrected. This is shown by the full line in the Figure.

Computation was again carried out on the corrected data to deduce the spectrum. This, however, did not differ more than 10 percent from the one derived without corrections. These are shown in Fig. 10. The average of the corrections for the small ion concentration has been found to be 7.5 percent from the results of $24 \mathrm{ex}$ periments. This shows that, if we limit the scanning range up to $0.3 \mathrm{~cm}^{2} / \mathrm{volt}$. sec. using the small-ion probe, the data without corrections would give the results without appreciable errors.

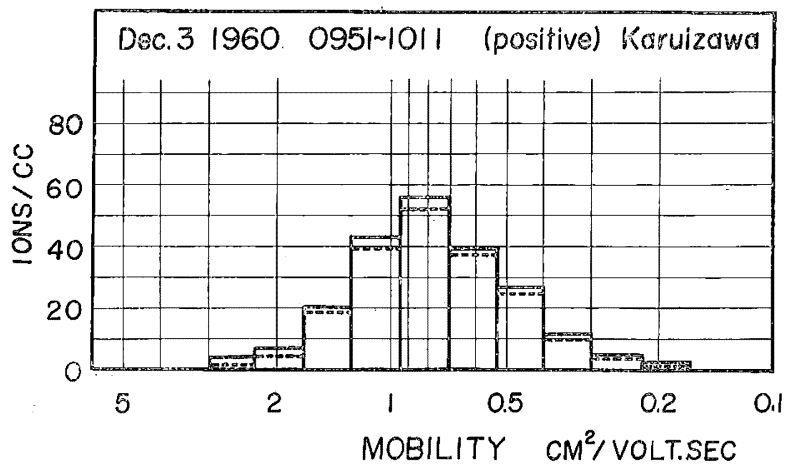

Fig. 10. Comparison of spectrum with the one derived from the data without corrections. (Broken line shows the latter.)

\section{3) Some effects of improper determinations of constants $R_{1}, R_{2}$, etc.}

Another cause of errors also may lie in wrong determinations of the constants of the electrometer system, e.g. $R_{1}, R_{2}$ etc. This has been examined as follows.

The currents to both electrodes can be written in the form,

$$
\begin{aligned}
& i_{1}=\Phi e\left[\int_{\kappa_{c}}^{\infty} f(\kappa) d \kappa+\frac{1}{\kappa_{c}} \int_{0}^{\kappa_{c}} \kappa f(\kappa) d \kappa\right], \\
& i_{2}=\Phi e\left[\int_{\kappa_{d}}^{\kappa_{c}} f(\kappa) d \kappa+\frac{1}{\kappa_{d}} \int_{0}^{\kappa_{d}} \kappa f(\kappa) d \kappa-\frac{1}{\kappa_{c}} \int_{0}^{\kappa_{c}} \kappa f(\kappa) d \kappa\right],
\end{aligned}
$$

If the air is free of the small ions, the total concentration of ions can be expressed practically by

$$
N=\int_{0}^{\kappa_{g}} f(\kappa) d \kappa
$$

where $\kappa_{g}$ denotes the greatest mobility of ions which are present. Since measurements are made in the region of the small ions, we can put $\kappa_{g} \ll \kappa_{d}$.

Then eqs. (7) and (8) become

$$
i_{1}=\Phi e N \cdot \frac{1}{\kappa_{c}}, \quad i_{2}=\Phi e N \cdot\left(\frac{1}{\kappa_{d}}-\frac{1}{\kappa_{c}}\right)
$$


So that there follows

$$
\frac{i_{1}}{a_{1}}-\frac{i_{2}}{a_{2}}=\Phi e N\left[\frac{1}{a_{1} \kappa_{c}}-\frac{1}{a_{2}}\left(\frac{1}{\kappa_{d}}-\frac{1}{\kappa_{c}}\right)\right]
$$

Inserting the relation of $\kappa_{c}$ to $\kappa_{d}$, (4), into (9), the term in the bracket becomes zero. Now, if $a_{1} R_{1} \neq a_{2} R_{2}$, we obtain from (1) putting $\frac{a_{2} R_{2}}{a_{1} R_{1}}=p$

$$
\frac{i_{1}}{a_{1}}-\frac{i_{2}}{a_{2}}=\frac{v_{1} / R_{1}}{a_{1}}-\frac{v_{2} / R_{2}}{a_{2}}=\frac{1}{a_{2} R_{2}}\left(v_{1}-v_{2}\right)-\frac{v_{1}}{a_{2} R_{2}}(1-p) .
$$

We observe the first term in the right hand side of the above equation, and so the second term gives the quantity of the correction for observed values.

Then, even if ions are absent in a scanning range, A-curve, in spite of being expected to be zero at all voltages of scanning, will decrease or increase with $V$ as $p$ is greater than unity or vice versa. If $p$ is known, the correction term can be evaluated from the data of B-curve if obtained simultaneously.

The small ion free air was easily produced in a sealed laboratory by producing abundant large ions with the aid of a Cottrell's discharger. An example of decrease in A-curve is shown in Fig. 11, which was obtained under such a condition using the intermediate-ion probe. The decrease showed good agreement with the amount of the correction estimated as above.

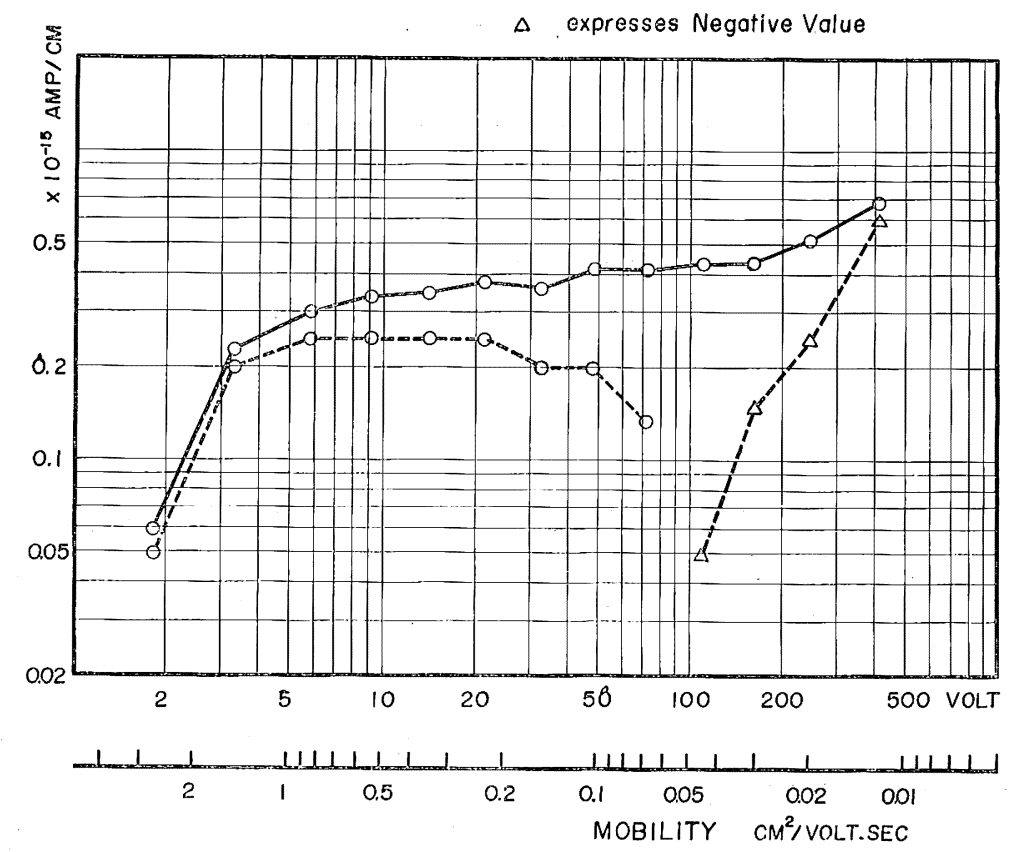

Fig. 11. Decrement in A-curve caused by improper determination of the circuit constant. Full line shows the corrected curve.

Strictly speaking, eq. (3), as well as eq. (4), does not hold good because the 
effect of stray field at the edges of the electrodes is neglected. Subsequently the ratio $R_{1} / R_{2}$, though determined to be exactly equal to $a_{2} / a_{1}\left(=l_{2} / l_{1}\right)$, is not yet proper. But these effects do not seem to cause any serious errors to the results, considering that the decrease in Fig. 11 has been well explained as described above.

Acknowledgements - - The author wishes to express his sincere thanks to Dr. Y. Tamura, Professor of Kyoto University, and Dr. S. Imamiti, Professor of Tokyo College of Science, for their kind guidance and encouragements throughout the work. His thanks are also due to Mr. H. Seniya, Chief of Karuizawa Weather Station and the members of that Station who afforded many facilities for the observations. The author is grateful to Mr. C. IsHII, Chief of the Upper Atmosphere Physics Laboratory of Meteorological Research Institute, Mr. G. Ishikawa, Mr. M. Kobayashi and the members of our Laboratory for their valuable advice and discussions, and also to Mr: I. KanAzawA for taking photographs.

\section{References}

Misaki, M., 1950: A method of measuring the ion spectrum, Pap. Met. Geophys., 1, 313-318. Misaki, M., 1960: Determination of air flow in an ion chamber (Preliminary examination for the study of ion spectrum.) Pap. Met. Geophys., 11, 348-355.

Junge, C.E., 1958: Advances in Geophysics IV, Atmospheric Chemistry, Academic Press Inc. Publishers, New York.

WhIPpLE, E.C.J., 1960: An improved technique for obtaining atmospheric ion mobility distributions. Journ. Geophys. Res. 65, 3679-3684.

\section{大気イオン・スペクトラムの研究 $(\mathbf{I})$}

一测定拈よび諳算の方法について一

$$
\text { 三㥓 方 郎 }
$$

前報では，1959 年飞新た飞設計製作した大気イオンの移動度スペクトロメーターの内部の気流分布に関 する実験結果を述べたが，4 9l/sec が適当な流量であることがわかつたので，これと基き，通気筒の一 部を改造して，スペクトロメータ一本来の機能をもた也て，湘定を開始した。

スペクトラム測定の方法は以前飞箫者が考案した原理による。イオン・プローブは等長で，直径の異本る

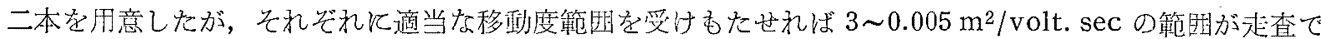
きる。しかし当面の研究範因は $3 \sim 0.1 \mathrm{~cm}^{2} /$ volt. sec として，いわゆる小イオン群のスペクトラム微細楬 造を明らかとすることを目的とした。

ここでは装置特よび実駼手順飞関する詳細と，装置の特性 (分解能等) とついて述べ，更に，清浄空気特 よび污濁空気中で行つた綜合検查の檢討から，実験上の組織的誤差とその補正法について述べた。 